\title{
DOES BOTULINUM TOXIN IMPROVE THE FUNCTION OF THE PATIENT WITH SPASTICITY AFTER STROKE?
}

\author{
Eduardo Cardoso ${ }^{1,2,6}$, Glícia Pedreira ${ }^{3}$, Antônio Prazeres², Nildo Ribeiro ${ }^{5}$, Ailton Melo ${ }^{2,4}$
}

\begin{abstract}
Post-stroke spasticity is an important cause of disability in adults, due to muscle hyperactivity, which results in limb stiffness and muscle spasm. The prognosis for these patients depends on several features such as early management and adequate physical therapy to avoid muscle shortening, pain, and their consequences. Although several papers have shown that intramuscular injections of botulinum toxin type A (BT-A) decreases spasticity in post-stroke patients, few authors have demonstrated functional improvement after this therapy. In order to assess if individualized BT-A injections improves upper limb function in post-stroke spastic patients, we prospectively followed 20 consecutive patients of 18 years of age or more with spastic hemiparesis secondary to stroke. Fulg-Meyer scale modified for upper limbs, measure of functional independence (MFI), Ashworth modified scale, and goniometry were applied in the beginning of the investigation and in the $16^{\text {th }}$ and $32^{\text {nd }}$ weeks. BT-A was applied at baseline and in the $16^{\text {th }}$ week. All subjects were submitted to rehabilitation therapy. All patients showed improvement according to Ashworth modified scale and increase in the range of motion, which were sustained until the $32^{\text {nd }}$ week $(p<0.05)$. The assessment of the first three parameters of the Fulg-Meyer scale and the evaluations of the motor part of the Functional Independence Measure showed statistically improvement until the end of the study. We conclude that proper choice of muscles and individualized doses of BT-A can improve function in selected post-stroke patients.
\end{abstract}

KEY WORDS: botulinum toxin, spasticity, stroke, rehabilitation.

\section{Toxina botulínica proporciona melhora funcional em pacientes com espasticidade secundária a acidente vascular cerebral ?}

RESUMO - Espasticidade secundária a acidente vascular cerebral (AVC) é importante causa de incapacidade em adultos. O prognóstico para estes pacientes depende de vários fatores como tratamento precoce e terapia física adequada, evitando encurtamento muscular, dor e outras conseqüências. Vários estudos têm demonstrado que aplicacões intramusculares de toxina botulínica do tipo A (TxB-A) reduzem a espasticidade após AVC, entretanto poucos autores observaram melhora funcional de membros superiores com esta terapêutica. Para determinar se aplicações individualizadas de TxB-A melhoram a função no membro superior espástico de pacientes com hemiparesia secundária a AVC, acompanhamos 20 pacientes com história de AVC entre 6 meses e 5 anos. A escala de Fulg-Meyer para membros superiores, a medida de independência funcional, a escala modificada de Ashworth e goniometria foram aplicadas no início da investigação, na $16^{\mathrm{a}}$ e $32^{\mathrm{a}}$ semanas. TxB-A foi aplicada no início do estudo e na $16^{\mathrm{a}}$ semana e todos os participantes foram tratados adicionalmente com fisioterapia. Observamos melhora na escala de Ashworth e aumento na amplitude de movimento em todos os pacientes até a $32^{a}$ semana $(p<0.05)$. A análise dos 3 primeiros parâmetros da escala de Fulg-Meyer e a parte motora da MIF mostraram melhora estatisticamente significante até o final do estudo. Concluímos que a escolha adequada dos músculos e doses individualizadas de TxB-A melhoram a função em pacientes com espasticidade pós-AVC.

PALAVRAS-CHAVE: toxina botulínica, espasticidade, acidente vascular cerebral, reabilitação.

Spasticity secondary to stroke is one of the most important cause of disability in adults; it interferes in the patient's rehabilitation and, particularly, in his functional recovery ${ }^{1-3}$. Botulinum toxin type A (BTA) causes a neuromuscular block in acetylcholine re- lease, thereby preventing neuromuscular transmission and muscle contraction and has been used for over a decade as one of the best treatment strategies for spasticity secondary to stroke $e^{4,5}$. Except for a few investigations, randomized, double-blind, placebo-

Division of Neurology and Epidemiology-Federal University of Bahia, Salvador BA, Brazil: ${ }^{1}$ Financial Aid from the Fundação de Amparo a Pesquisa do Estado da Bahia (FAPESB), Brazil; ${ }^{2}$ Professor of Neurology; ${ }^{3}$ Occupational Therapist, Financial Aid from the Coordenação de Aperfeiçoamento de Pessoal de Nível Superior (CAPES), Brazil; ${ }^{4}$ Investigator of the Brazilian National Research Council (CNPq), Brazil; ${ }^{5}$ Physiotherapist.

Received 10 November 2006, received in final form 17 January 2007. Accepted 22 March 2007. 
controlled trials have not evidenced functional gain after the use of BT-A $A^{6,7}$. On the other hand, on a recent editorial, Bakheit ${ }^{8}$ emphasizes the need of series of case studies to evaluate the efficacy of botulinum toxin in the treatment of post-stroke spasticity. The author observes that several issues related to stroke, such as size of the affected area, neglect, anosognosia, and other cognition aspects are confounding factors difficult to control in double-blind studies.

For those patients with a functionally useless arm, spasticity may interfere with self-care tasks, which influences the overall quality of life ${ }^{2}$. Thus one of the major objectives in the treatment of this group of patients is to first establish the degree of possible functional improvement of upper extremity. However, in most studies, such functional improvement after BTA treatment has not been objectively and accurately determined ${ }^{8}$.

The purpose of this study was to establish whether individualized BT-A injection improves upper limb function in post-stroke spastic patients.

\section{METHOD}

This study was approved by the ethical committee of the Federal University of Bahia - Brazil, and was performed according the 1964 Declaration of Helsinki. All patients signed the informed consent form prior to taking part in any procedure of this study. The botulinum toxin was provided by the Health Secretariat of the State of Bahia, Brazil, to be used in patients with spasticity.

An open, prospective clinical trial was carried out at the Neurosciences Outpatient Clinic, in the Magalhães Neto Pavilion (University Hospital Prof. Edgard Santos) with consecutive patients of both genders, older than 18 years, with spastic hemiparesis secondary to stroke, with a time interval from the vascular event between 6 months to 5 years. Patients with liver, blood or kidney diseases; pregnant or nursing women; or cases of aphasia, dementia or fibrotic retraction of the affected muscles were excluded from the investigation. During the follow up patients could not use antispastic or sedative drugs.

To measure the functional gain of the affected upper limb, spasticity and range of motion, the Fulg-Meyer scale modified for upper limbs, measure of functional independence (MFI), Ashworth modified scale, and goniometry ${ }^{9-12}$ were applied in the beginning of the investigation and in the $16^{\text {th }}$ and $32^{\text {nd }}$ weeks. After individualized selection of muscles and doses, BT-A was applied at baseline and in the $16^{\text {th }}$ week. All subjects were submitted to rehabilitation therapy.

The dose of BTX-A (Dysport ${ }^{\oplus}$ ) was administered according to each patient's individual pattern of spasticity, with doses not exceeding $1500 \mathrm{U}$ per session and not more than $300 \mathrm{U}$ per muscle (Table). The dilution was standardised: one vial ( $500 \mathrm{U}$ ) was diluted with $2.5 \mathrm{~mL}$ normal saline The injections were administered using anatomical references.
Demographic variables were presented as means and standard deviation. Data with $\mathrm{p}<5 \%$ were considered significant. Data were entered in databank software, and analyzed through SPSS 9.0; the paired-samples Student's $t$ test and ANOVA were used to compare the means.

\section{RESULTS}

From November 2004 to February 2006, 20 patients with spastic hemiparesis secondary to stroke were evaluated, and all of them were followed up until the end of the investigation. Fifty per cent $(50 \%)$ of the subjects were male, mean age was 55.3 years, and mean time from the cerebrovascular event was 3.4 years. Only one patient presented a dominant left side, and the left cerebral hemisphere was affected in $55 \%$ of the patients.

All patients showed improvement according to Ashworth modified scale and increase in the range of motion, which were sustained until the $32^{\text {nd }}$ week $(p<0.05)$. The assessment of the first three parameters of the Fulg-Meyer scale modified for upper limbs, which assess voluntary activity, wrist stability, and hand is shown in Figure 1. Improvement was ascertained, particularly in the $2^{\text {nd }}$ evaluation; and even though the differences were still significant when the first evaluation is compared to the third, there was a slight decrease in all parameters assessed in the $3^{\text {rd }}$ evaluation. The evaluations of the Functional Independence Measure (FIM) (motor portion) show that patients had their functions gradually improved until the end of the study $(p<0,05)$ (Fig 2$)$. Side effects

\section{Assessment by the Modified Fulg-Meyer Scale for upper limbs}

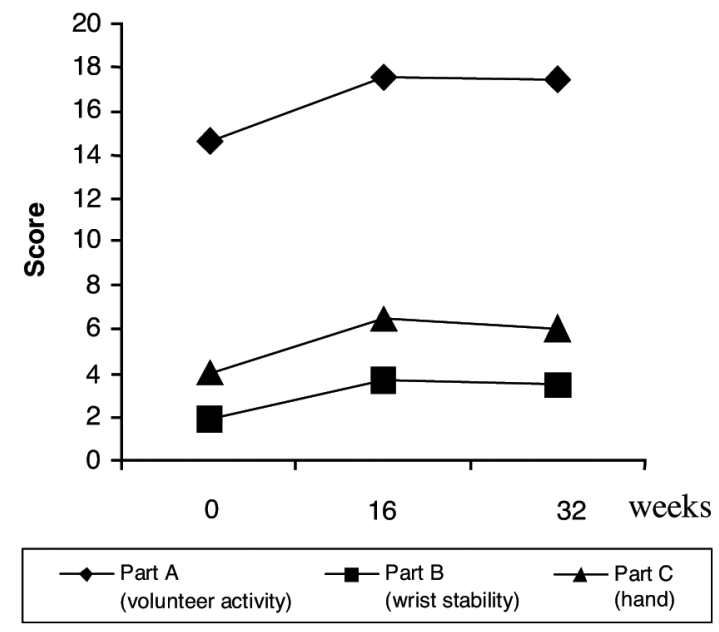

Fig 1. Assessment by the modified Fulg-Meyer Scale (Parts A, B and C) for upper limbs. 


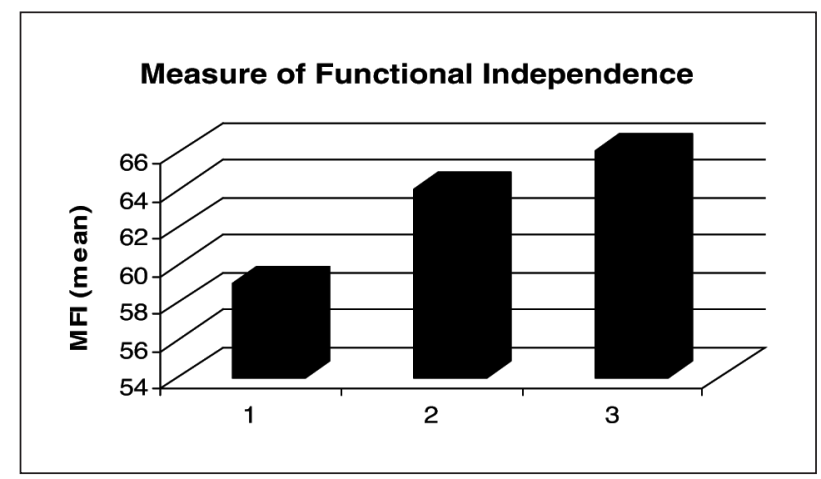

Fig 2. Assessment by measure of functional independence (motor portion).

were transient and observed in only three patients, and included pain on the application site in two patients, and local edema in one patient.

\section{DISCUSSION}

This study shows that the use of individualized doses of botulinum toxin type $A$ in the upper limbs improves function of post-stroke spastic patients. In a study with similar design and different assessment scales, Slawek et al. ${ }^{13}$ achieved conflicting results on functional improvement. In their research, only 7 out of 21 patients were able to perform the evaluation test (Nine Hole Peg Test) at baseline, and they did not achieve statistically significant improvements until the end of the study, although, in some cases, there was marked change.

In our study, individualized doses of botulinum toxin were used according to prescription from the rehabilitation team, which conflicts with the strict application schemes used in double-blind studies ${ }^{4,11,12}$. On the other hand, in a recent paper, Bakheit et al. had shown that the search for appropriate dosages favors the performance of patients with spasticity, as patients who received a $1000 \mathrm{u}$ dose performed better than those who received a dose of $1500 \mathrm{u}^{14}$. By selecting, patient by patient, the muscles where to apply BT-A, we observed that most of our patients had spastic pronation of the forearm, and were able to reach a neutral position or to perform a full supine rotation after the use of botulinum toxin. This

Table. BTX-A doses (Dysport ${ }^{\circledR}$ ) in all patients (mean total dose, and doses per muscle).

\begin{tabular}{|c|c|c|c|c|c|c|c|c|c|c|c|c|}
\hline \multirow[t]{2}{*}{ Patient } & \multicolumn{11}{|c|}{ Muscle } & \multirow{2}{*}{$\begin{array}{c}\text { Total } \\
\text { dosage }(U)\end{array}$} \\
\hline & PM & GD & B & $B-R$ & FCU & FCR & FDS & FDP & PT & OP & TB & \\
\hline 1 & 300 & 200 & 200 & 150 & - & - & - & - & - & - & - & 850 \\
\hline 2 & - & - & - & - & 150 & 200 & 100 & - & 150 & - & - & 600 \\
\hline 3 & 200 & - & 200 & 150 & - & - & 150 & - & 150 & - & - & 850 \\
\hline 4 & 200 & 200 & - & - & 150 & 200 & 150 & - & & - & 200 & 1100 \\
\hline 5 & - & - & 200 & 200 & 150 & 150 & 150 & - & & - & - & 850 \\
\hline 6 & 300 & 200 & - & - & - & - & 150 & - & 150 & - & 200 & 1000 \\
\hline 7 & 200 & - & 200 & 200 & - & - & 150 & 150 & & - & - & 900 \\
\hline 8 & 250 & - & 300 & 200 & 150 & 150 & 150 & 150 & 150 & - & - & 1500 \\
\hline 9 & 300 & - & 200 & 200 & 150 & 150 & 150 & 150 & 150 & 50 & - & 1500 \\
\hline 10 & 200 & 200 & 200 & - & - & - & 150 & - & & 75 & - & 825 \\
\hline 11 & - & - & 200 & - & 150 & 150 & 150 & 150 & & - & - & 800 \\
\hline 12 & - & - & - & - & 150 & - & - & 200 & 200 & - & - & 550 \\
\hline 13 & 250 & - & 300 & 200 & 150 & 150 & 150 & 150 & 150 & - & - & 1500 \\
\hline 14 & 200 & - & - & - & - & - & 200 & 150 & & - & 200 & 750 \\
\hline 15 & - & - & - & - & 150 & 200 & - & 100 & 150 & - & - & 600 \\
\hline 16 & 300 & 200 & 200 & 200 & 150 & 200 & - & - & 150 & - & - & 1400 \\
\hline 17 & 200 & 200 & 200 & 150 & 150 & 150 & 150 & 150 & 150 & - & - & 1500 \\
\hline 18 & 300 & - & 200 & 200 & 150 & 150 & 150 & 150 & 150 & - & & 1450 \\
\hline 19 & 200 & 200 & - & - & 150 & 200 & 150 & - & & - & 200 & 1100 \\
\hline 20 & 250 & - & 300 & 200 & 150 & 150 & 150 & 150 & 150 & - & - & 1500 \\
\hline Mean dose/muscle & 250 & 200 & 225 & 187,5 & 150 & 170 & 150 & 150 & 150 & 62,5 & 200 & 1056,2 \\
\hline \& mean total dose & & & & & & & & & & & & \\
\hline
\end{tabular}

PM, pectoralis major; B, biceps brachii; B-R, brachioradialis; FCU, flexor carpii ulnaris; FCR, flexor carpii radialis; FDS, flexor digitorum superficialis; FDP, flexor digitorum profundus; PT, pronator teres; Triceps brachii; OP, oponent pollicis. 
aspect is typically not addressed by most authors. It is clear, however, that supine rotation reflects functional gains, and in our cases, there was no further loss of other functions. Another aspect to be observed is that shoulder adduction and internal rotation from post-stroke spasticity is markedly reduced after application of BT-A in the greater pectoral and/or latissimus dorsi muscles, which increases range of shoulder motion, thus increasing functional gain according to the scales we used.

One aspect to be discussed is the use of series of cases design to assess function of post-stroke spastic patients in whom botulinum toxin was applied, instead of double-blind studies. It is very difficult for the investigator or the patient to remain blind after application of botulinum toxin versus placebo, as there will be a decrease of muscle strength and spasticity whenever proper doses of the toxin are applied. In our study, the evaluators did not know whether the patient had already taken BT-A or not, and used standardized scales, which lessens the assessment bias from prior knowledge of the fact.

In this investigation, we observed a slight decrease in the improvement of the function in the third evaluation, compared to the second. Even though the difference is not statistically significant, the last assessment was performed after 4 months of use of BT-A, which probably shows the consequence of neuronal reorganization and recurrence of spasticity, in spite of the work of the physical rehabilitation team. It should be stressed that botulinum toxin was used only in patients who scored at least 2 on the Ashworth scale at baseline. This is conflicting to what some authors advocate ${ }^{13}$, as they believe function improvement after injection of botulinum toxin only occurs in a small group of patients with mild or moderate spasticity. We can conclude, however, that if there is no joint motion limitations, the functional gain of post-stroke spastic patient will depend on the dosage being appropriate, and on the selection of the muscles in which the toxin will be injected, according to the goals established by the rehabilitation team along with the patient.

\section{REFERENCES}

1. Nakaiama H, Jorgensen HS, Raaschou HO, et al. Recovery of upper extremity function in stroke patients: the Copenhagen stroke study. Arch Phys Med Rehab 1994;75:394-398.

2. Rousseaux M, Kozlowski O, Froger J. Efficacy of botulinum toxin in upper limb function of hemiplegic patients. J Neurol 2002;249:76-84.

3. Bergfeldt U, Borg K, Kullander K, Julin P. Focal spasticity therapy with botulinum toxin: effects on function, activities of daily living and pain in 100 adult patients. J Rehabil Med 2006;38:166-171.

4. Simpson DM, Alexander DN, O'Brien CF, et al. Botulinum toxin type $A$ in the treatment of upper extremity spasticity: a randomised, double-blind, placebo-controlled trial. Neurology 1996;46:1306-1310.

5. Cardoso E, Rodrigues B, Lucena R, Oliveira IR, Pedreira G, Melo A. Botulinum toxin type A for the treatment of the upper limb spasticity after stroke: a meta-analysis. Arq Neuropsiquiatr 2005;63:30-33.

6. Sheean G. Botulinum toxin treatment of adult spasticity : a benefit-risk assessment. Drug Saf 2006;29:31-48.

7. Brashear A, Gordon MF, Elovic E, et al. Intra-muscular injection of botulinum toxin for the treatment of wrist and finger spasticity after a stroke. N Engl J Med 2002;347:395-400.

8. Bakheit AM. Optimising the methods of evaluation of the effectivess of botulinum toxin treatment of post-stroke muscle spasticity. J Neurol Neurosurg Psychiatry 2004;75:665-666.

9. Brin M. The Spasticity Study Group. Dosing, administration and a treatment algorithm for use of botulinum toxin A for adult-onset spasticity. Muscle Nerve 1997;20(Suppl 6):S208-S220.

10. Richardson D, Sheean G, Werring D, et al. Evaluating the role of botulinum toxin in the management of focal hypertonia in adults. J Neurol Neurosurg Psychiatry 2000;68:707-712.

11. Bakheit AMO, Pittock S, Moore AP, et al. A randomised, double-blind, placebo controlled study of the efficacy and safety of botulinum toxin type A in upper limb spasticity in patients with stroke. Eur J Neurol 2001;8:559-565.

12. Bhakta BB, Cozens JA, Chamberlian MA, Bamford JM. Impact of botulinum toxin type A on disability and carer burden due to arm spasticity after stroke: a randonised double blind placebo controlled trial. J Neurol Neurosurg Psychiartry 2001;70:821.

13. Slawek J, Bogucki A, Reclawowicz D.Botulinum toxin type A for upper limb spasticity following stroke: an open-label study with individualised, flexible injection regimens. Neurol Sci 2005;26:32-39.

14. Bakheit AMO, Thilmann AF, Ward AB, et al. A randomized, doubleblind, placebo-controlled, dose-ranging study to compare the efficacy and safety of three doses of botulinum toxin type A (Dysport) with placebo in upper limb spasticity after stroke. Stroke 2000;31:3402-3406. 